\title{
Identification of biomarkers for endometriosis in eutopic endometrial cells from patients with endometriosis using a proteomics approach
}

\author{
JIN-HEE HWANG ${ }^{1}$, JIN-JU OH ${ }^{2}$, TAO WANG ${ }^{1}$, YONG-CHENG JIN ${ }^{3}$, JAE-SUNG LEE ${ }^{1}$, \\ JONG-RYEOL CHOI ${ }^{4}, \mathrm{KYU}_{-} \mathrm{SUP}_{\mathrm{LEE}}{ }^{4}$, JONG-KIL JOO ${ }^{4}$ and HONG-GU LEE ${ }^{1}$
}

\begin{abstract}
${ }^{1}$ Department of Animal Science and Technology, College of Animal Bioscience \& Technology, Konkuk University, Seoul 143-701; ${ }^{2}$ Natural Product Clinical Research Center, Clinical Research Center, Pusan National University School of Medicine, Busan 602-739, Republic of Korea; ${ }^{3}$ Department of Animal Science, College of Animal Science and Veterinary Medicine, Jilin University, Changchun 130062, P.R. China; ${ }^{4}$ Department of Obstetrics and Gynecology, School of Medicine, Pusan National University, Yangsan, Gyeongnam 626-770, Republic of Korea
\end{abstract}

Received February 12, 2013; Accepted March 15, 2013

DOI: $10.3892 / \mathrm{mmr} .2013 .1469$

\begin{abstract}
Endometriosis is a gynecological disease defined as the presence of endometrial tissue outside the uterine cavity, which is caused by various factors. Proteomic analysis of two sets of eutopic endometrial cells collected from the menstrual blood of females with $(n=6 ; n=3)$ or without $(n=6$; $\mathrm{n}=3$ ) endometriosis was performed to identify novel potential biomarkers for endometriosis. The data revealed that samples from endometriosis patients had stem cell characteristics, as they had higher mRNA expression levels of octamer-binding transcription factor 4 (Oct-4), C-X-C chemokine receptor type 4 (CXCR4), SRY-box containing gene 2 (SOX2) and mesenchymal-epithelial transition factor (MET) compared with that of the normal controls. Three proteins, collapsin response mediator protein 2 (CRMP2), ubiquitin carboxyl-terminal hydrolase isozyme L1 (UCH-L1) and myosin regulatory light polypeptide 9 (MYL9), were simultaneously identified from the two sets of samples from females with or without endometriosis by two-dimensional electrophoresis (2-DE). A difference in CRMP2 expression was confirmed with western blotting. Taken together, the results suggest that CRMP2 plays a role in the pathogenesis of endometriosis.
\end{abstract}

Correspondence to: Dr Hong-Gu Lee, Department of Animal Science and Technology, College of Animal Bioscience \& Technology, Konkuk University, 120 Neungdong-ro, Gwangjin-gu, Seoul 143-701, South Korea

E-mail: hglee66@konkuk.ac.kr

Dr Jong-Kil Joo, Department of Obstetrics and Gynecology, School of Medicine, Pusan National University, Beomeo-ri, Mulgeum-eup, Yangsan, Gyeongnam 627-770, South Korea E-mail: jongkilj@hanmail.net

Key words: collapsin response mediator protein 2, endometriosis, eutopic endometrial cells, menstrual blood, proteomics

\section{Introduction}

Endometriosis is a gynecological disease defined as the presence of endometrial tissue outside the uterine cavity. This tissue is located in the peritoneum, ovary or fallopian tube and more rarely in the pleura, lung or brain. Endometriosis occurs in $5-20 \%$ of females with pelvic pain, $20-50 \%$ of infertile females and $6-10 \%$ of females of reproductive age (1). The causes of this disease include retrograde menstruation, endometrium abnormalities, peritoneal environment changes, increased angiogenesis, inadequate immunological reactions and genetic and environmental factors $(1,2)$.

Several hypotheses linking stem cells and endometriosis have emerged and previous studies have indicated that endometrium-derived cells, particularly stem and progenitor cells, contribute to the initiation of endometriosis $(3,4)$. Furthermore, this group observed stem cell and progenitor cell activity in the basal layers of the endometrium and ectopic endometrium. This finding supports the 'retrograde menstruation theory', which suggests that endometriosis arises from the implantation of endometrial tissues due to retrograde flow of menstruation blood containing these tissues (5). It was reported that bone marrow-derived cells may differentiate into endometrial tissues and contribute to endometriosis $(6,7)$. Endometrial tissues also contain stem cells with strong proliferative characteristics, given that cells in these tissues are rapidly shed and regenerated during the menstruation cycles. The abnormal existence or hyperplasia of cells is thought to be associated with the pathogenesis of a number of diseases (8). Numerous putative stem cell markers have been previously described $(9,10)$. Differentiated cells are produced by the ectopic expression of specific transcription factors, including SRY-box containing gene 2 (SOX2), octamer-binding transcription factor 4 (Oct-4), Krüeppel-like factor 4 (KLF-4), homeobox protein NANOG (NANOG), C-X-C chemokine receptor type 4 (CXCR4) and cellular homolog of the oncogenic retrovirus v-myc oncogene (c-Myc), and subsequently form pluripotent stem cells (11-13). Recent studies have demonstrated that stem cell markers, 
Table I. Primers used for quantitative real-time polymerase chain reaction (PCR).

\begin{tabular}{lll}
\hline Name & Accession no. & \\
\hline -tubulin & NM_006082.2 & Frimers $\left(5^{\prime}-3^{\prime}\right)$ \\
Oct-4 & NM_203289.3 & R: CTTGGCATACATCAGGTCAA \\
& & F: GGAAGGTATTCAGCCAAACG \\
CXCR4 & NM_003467.2 & R: TAGCCTGGGGTACCAAAATG \\
SOX2 & FM_003106.2 & R: GATCTTCCTGCCCACCATCT \\
MET & & F: GCACATGAACACACATAGACCACCT \\
& NM_000245.2 & R:TGCTGCGAGTAGGACACATGCTGTAGGG \\
& & F: GGGTCGCTTCATGCAGGTTGTGGT
\end{tabular}

Oct-4, octamer-binding transcription factor 4; CXCR4, C-X-C chemokine receptor type 4; SOX2, SRY-box containing gene 2; MET, mesenchymal-epithelial transition factor; F, forward; R, reverse.

including SOX2, Oct-4 and CD117 antigen (c-kit) are expressed in the endometrium $(14,15)$.

Proteomics is the study of protein expression in cells, tissues and whole organisms. Proteomic methods have been used as a therapeutic tool for the diagnosis of ovarian, lung, colon and endometrial cancers $(16,17)$. This approach is a non-surgical assessment and is crucial in diagnosis. Molecular screening methods generate an index for investigating new biological markers by comparing protein expression levels between patients and healthy controls (18). Several groups have used proteomics to study endometriosis by analyzing serum, peritoneal fluid, eutopic and ectopic endometrial tissues and endometrial fluid (19-21). The aim of our study was to determine whether eutopic endometrial cells recovered from menstrual blood express undifferentiated stem cell markers. In addition, we aimed to identify novel potential biomarkers for endometriosis through a comparative proteomic analysis of endometrial cells from patients with and without endometriosis.

\section{Materials and methods}

Subjects. This study was approved by the human Ethics Committee of the Pusan National University Hospital (Institutional Review Board: 2008072) and all of the females recruited for the study signed a consent form prior to participation. Two independent study populations were recruited: the first for identification of biomarkers $(n=12)$ and the second for biomarker validation $(n=6)$. The patients included individuals with a laparoscopic diagnosis of endometriosis aged between 25 and 40 years. Half the females had advanced endometriosis and the other half did not have endometriosis, adenomyosis or leiomyoma.

Eutopic endometrial cells derived from menstrual blood. The eutopic endometrial cells were isolated from $\sim 1 \mathrm{ml}$ menstrual blood collected with a suction catheter on days 2-4 of the menstrual cycle. Menstrual blood samples were cultured in Dulbecco's modified Eagle's medium (DMEM)/F-12 with $5 \%$ fetal bovine serum (FBS; HyClone Laboratories, Inc.,
Logan, UT, USA) and $0.2 \%$ collagenase (Invitrogen Life Technologies, Carlsbad, CA, USA) at $37^{\circ} \mathrm{C}$ with $5 \% \mathrm{CO}_{2}$ for 1 h. To isolate eutopic endometrial cells, the media were centrifuged at $300 \mathrm{x} \mathrm{g}$ for $10 \mathrm{~min}$. The cells were cultured in DMEM supplemented with $10 \%$ FBS, $1 \%$ penicillin/streptomycin (v/v) and $1 \%$ amphotericin B (v/v) (Sigma-Aldrich, St. Louis, MO, USA) for 2 days at $37^{\circ} \mathrm{C}$ under $5 \% \mathrm{CO}_{2}$. The cells were then washed three times with phosphate-buffered saline (PBS) and resuspended in DMEM containing 10\% FBS. After 2 weeks, the eutopic endometrial cells were collected following detachment with trypsin (Lonza Verviers, Belgium) and then washed twice with PBS.

RNA extraction and quantitative real-time polymerase chain reaction $(P C R)$. Total RNA was extracted from the eutopic endometrial cells using TRIzol reagent (Invitrogen Life Technologies) according to the manufacturer's instructions. An aliquot of total RNA $(3 \mu \mathrm{g})$ was used as a template for single-stranded cDNA synthesis by incubating the RNA with reverse transcriptase (Invitrogen Life Technologies) at $37^{\circ} \mathrm{C}$ for $1 \mathrm{~h}$. PCR amplification of the selected genes was performed using the appropriate forward and reverse primers (Table I). Real-time PCR was performed in $20 \mu 1$ reactions in 96-well plates using a MyiQ ${ }^{\mathrm{TM}}$ Single-Color Real-Time PCR Detection System (Bio-Rad, Hercules, CA, USA). The reaction conditions were optimized using an $\mathrm{iQ}^{\mathrm{TM}} \mathrm{SYBR}^{\circledR}-$ Green Supermix Kit (Bio-Rad). Gene expression was analyzed using the $2^{-\Delta \Delta C T}$ method (22).

Protein extraction. Total proteins were extracted from endometrial cells with $8 \mathrm{M}$ urea, 4\% (w/v) 3-[(3-cholamidopropyl) dimethylammonio]-1-propanesulfonate (CHAPS), 1\% (w/v) ethylenediaminetetraacetic acid (EDTA), $10 \mathrm{mM}$ Tris/ $\mathrm{HCl}$ ( $\mathrm{pH}$ 8.3) and protease inhibitor cocktail (GE Healthcare, Piscataway, NJ, USA). Briefly, cells were incubated with the above cell lysis buffer for $30 \mathrm{~min}$ at room temperature and stirred every $5 \mathrm{~min}$. The protein samples were then centrifuged at $18,000 \mathrm{x} \mathrm{g}$ for $15 \mathrm{~min}$ at $20^{\circ} \mathrm{C}$ and the supernatant was collected. Protein concentrations of all the samples were determined using 
Table II. Identification of proteins corresponding to spots on 2-DE gels of eutopic endometrial-derived cells showing differences in protein expression (control vs. endometriosis) during days 2-4 of the menstrual cycle in females with and without endometriosis.

\begin{tabular}{lccccc}
\hline Spot no. & Protein name & MW $(\mathrm{kDa}) / \mathrm{p} I$ & MOWSE score & UniprotKB/Swiss-Prot entry & Expression \\
\hline 1 & CRMP2 & $62.7 / 5.95$ & 590 & $\mathrm{Q} 16555$ \\
2 & UCH-L1 & $25.1 / 5.33$ & 132 & P09936 \\
3 & MYL9 & $19.9 / 4.80$ & 88 & P24844 \\
\hline
\end{tabular}

2-DE, two-dimensional electrophoresis; MW, molecular weight; MOWSE, molecular weight search.

a PlusOne 2-D Quant Kit (GE Healthcare). Aliquots of the protein samples were stored at $-80^{\circ} \mathrm{C}$ until analysis.

Two-dimensional electrophoresis (2-DE) and protein identification by electrospray ionization-quadrupole-time of flight/ mass spectrometry (ESI-Q-TOF/MS). Two separate 2-DE analyses were performed in order to analyse the difference of these two independent study populations, separately. Electrophoretic separation of total cell proteins was performed using a previously described method (23). Briefly, the protein samples of eutopic endometrial cells were diluted in isoelectric focusing (IEF) buffer containing $9 \mathrm{M}$ urea, $2 \mathrm{M}$ thiourea, 4\% CHAPS, $500 \mathrm{mM}$ EDTA, $0.002 \%$ (w/v) bromophenol blue, $75 \mathrm{mM}$ dithiothreitol (DTT) and 1\% (v/v) pharmalyte (pH 3-10 NL). A total volume of $350 \mu \mathrm{l}$ containing $100 \mu \mathrm{g}$ pooled proteins was then loaded onto a $\mathrm{pH}$ 3-10 NL immobilized $\mathrm{pH}$ gradient strip (GE Healthcare; $18 \mathrm{~cm}$ ). After $12 \mathrm{~h}$ rehydration at $20^{\circ} \mathrm{C}$, IEF was performed with an IEF electrophoresis unit (GE Healthcare) under the following conditions: a linear ramp from 500 to $1,000 \mathrm{~V}$ for $1 \mathrm{~h}$ and a constant voltage of $8,000 \mathrm{~V}$ for $6 \mathrm{~h}$ to deliver a total of $56,000 \mathrm{Vh}$. Following IEF, the strips were equilibrated twice for $15 \mathrm{~min}$ each in equilibration buffer containing $50 \mathrm{mM}$ Tris- $\mathrm{HCl}$ (pH 8.8), $6 \mathrm{M}$ urea, 2\% sodium dodecyl sulfate (SDS), $30 \%$ glycerol and $0.002 \%$ (w/v) bromophenol blue. For the first equilibration, the buffer contained $1 \%$ DTT and for the second equilibration the buffer contained $135 \mathrm{mM}$ iodoacetamide. An Ettan DALT 2-D gel system (GE Healthcare) was used for electrophoresis in the second dimension. The equilibrated strips were inserted into the top of the $12 \%$ SDS-polyacrylamide gel electrophoresis (PAGE) gel. The gels were then stained using a PlusOne Silver Staining Kit (GE Healthcare). Spot detection, pair matching and normalization were performed using ProteomWeaver software (Definiens, Munich, Germany). Ratios of spot intensities for the control and endometriosis patients were calculated. Spots with intensities showing a change of $>2$-fold were selected for ESI-Q-TOF/ MS analysis. The details of ESI-Q-TOF/MS analysis have been described previously (24).

Western blot analysis. Eutopic endometrial proteins $(25 \mu \mathrm{g})$ were loaded onto a $10 \%(\mathrm{w} / \mathrm{v})$ polyacrylamide gel and separated with electrophoresis. Proteins in the gels were transferred onto nitrocellulose membranes using a Trans-Blot ${ }^{\circledR}$ SD Semi-Dry Transfer Cell (Bio-Rad). The membranes were blocked overnight at $4^{\circ} \mathrm{C}$ with 5\% non-fat dried milk (BD Biosciences, Franklin Lakes, NJ, USA) in Tris-buffered saline with Tween-20 [TBST; 20 mM Tris- $\mathrm{HCl}$ (pH 7.6), $137 \mathrm{mM} \mathrm{NaCl}$ and $0.01 \%$ Tween-20]. The membranes were then incubated with an anti-collapsin response mediator protein 2 (CRMP2) antibody (ab62661, 1:10000 dilution; Abcam, Cambridge, MA, USA) for $3 \mathrm{~h}$ at $4^{\circ} \mathrm{C}$. The membranes were washed three times with TBST and incubated with polyclonal goat anti rabbit IgG-horseradish peroxidase (HRP; ab6721, 1:3000 dilution; Abcam). Immunoreactive proteins on the membrane were visualized by enhanced chemiluminescence using an ECL-Plus Detection Kit (GE Healthcare) and exposure to X-ray film (Fujifilm Corporation, Tokyo, Japan) for 1-5 min. The film was then scanned and the bands were quantified using ImageJ 1.43 software (http://rsb.info.nih.gov/ $\mathrm{ij} /$ download.html). Protein expression levels were normalized to those of $\beta$-actin on the same membrane.

Statistical analysis. Values are expressed as mean \pm standard error of the mean (SEM). Student's t-test was used to compare results from the two groups of study subjects. $\mathrm{P}<0.05$ was considered to indicate a statistically significant difference.

\section{Results}

Real-time PCR verification of undifferentiated stem cell markers overexpressed in primary eutopic endometrial cells collected from menstrual blood. The mRNA expression levels of undifferentiated stem cell markers (Oct-4 and CXCR4) in eutopic endometrial cells from endometriosis patients and healthy controls were compared using real-time PCR. Compared to the controls, mRNA expression of Oct- 4 and CXCR4 was 21.36- and 23.5-fold higher, respectively, in the endometriosis patients (Fig. 1). These results confirm that the mRNA expression of undifferentiated stem cell markers was higher in the endometriosis patients.

2-DE protein profiles of eutopic endometrial cells collected from the menstrual blood of females with or without endometriosis. 2-DE analysis was performed to characterize differences of protein expression in eutopic endometrial cells from endometriosis patients and normal controls. Proteins corresponding to three selected spots on the 2-DE gel were identified using ESI-Q-TOF/MS. These proteins had a lower ( $\geq 3$-fold) expression in endometriosis patients compared to that of the controls. Using this technique, we identified three differentially expressed proteins as CRMP2, UCH-L1 and MYL9 (Fig. 2; Table II).

Real-time PCR analysis of undifferentiated stem cell marker overexpression in the second set of eutopic endometrial cells. 


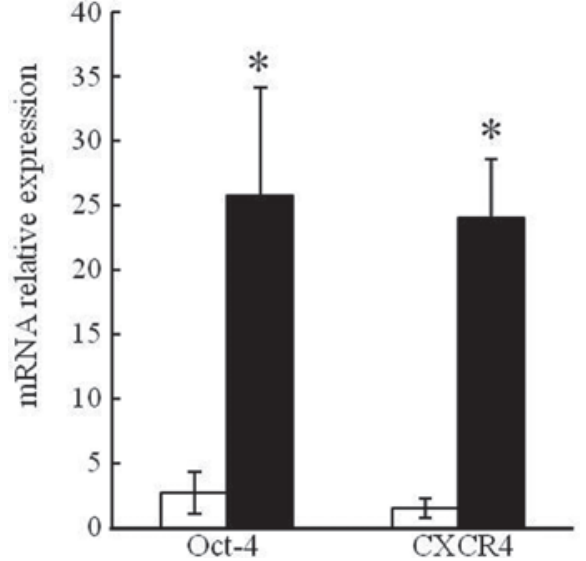

Figure 1. Relative mRNA expression of octamer-binding transcription factor 4 (Oct-4) and C-X-C chemokine receptor type 4 (CXCR4) in eutopic endometrial cells from females with and without endometriosis (first set of samples). Values are expressed as the means \pm standard error of the mean (SEM; $\mathrm{n}=6)$. ${ }^{*} \mathrm{P}<0.05$, compared to the control.

A

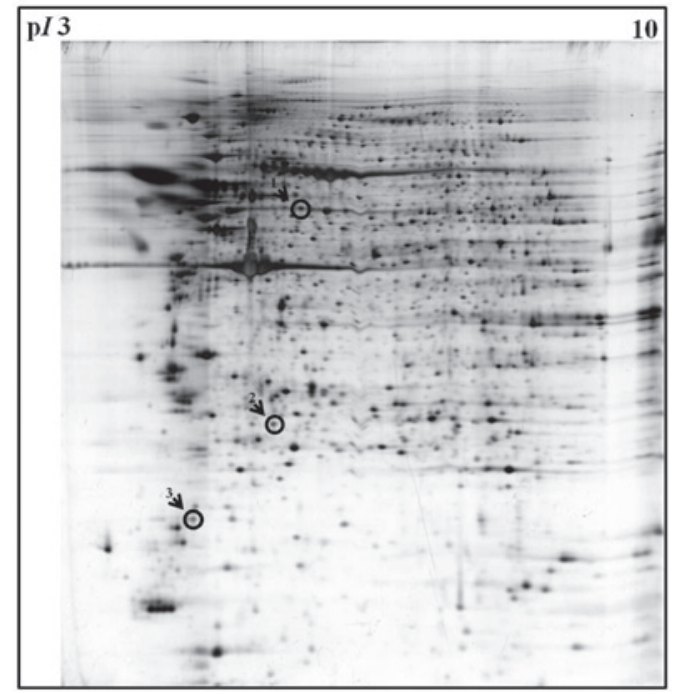

B

\begin{tabular}{|c|c|c|c|c|c|}
\hline \multicolumn{2}{|c|}{1} & \multicolumn{2}{c|}{2} & \multicolumn{2}{c|}{3} \\
\hline $\mathrm{N}$ & $\mathrm{E}$ & $\mathrm{N}$ & $\mathrm{E}$ & $\mathrm{N}$ & $\mathrm{E}$ \\
\hline $\mathrm{N}$ & & - & & & \\
\hline
\end{tabular}

Figure 2. Representative silver-stained two-dimensional electrophoresis (2-DE) gel images of the eutopic endometrial cells from females with or without endometriosis. Total proteins from human endometrial-derived cells were separated by 2-DE using a pH 3-10 gel $(18 \mathrm{~cm})$. (A) Representative gel contains pooled proteins from females with $(\mathrm{E})$ or without $(\mathrm{N})$ endometriosis. (B) Boxes highlight the three spots representing differentially expressed proteins whose identification is shown in Table II.

The mRNA expression of four undifferentiated stem cell markers, including Oct-4, CXCR4, SOX2 and mesenchymalepithelial transition factor (MET) in the second set of collected samples were analyzed using real-time PCR. Partially consistent with the results from the first set of samples, mRNA expression levels of Oct-4, CXCR4, SOX2 and MET were 16.9-, 22.36-, 4.88- and 16.95-fold higher, respectively, in the endometriosis patients compared to those in the controls

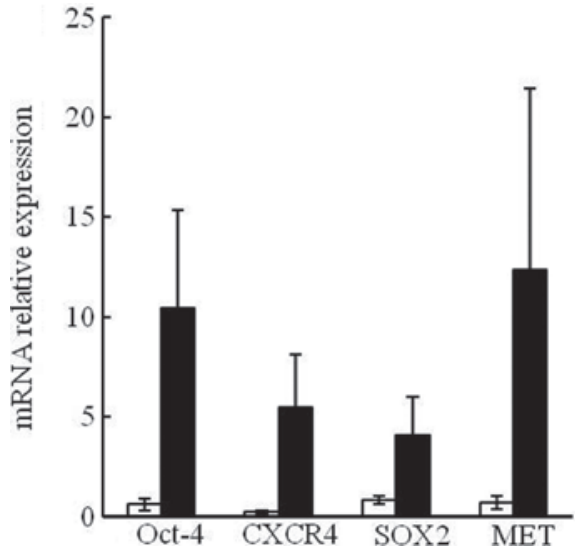

Figure 3. Relative mRNA expression of octamer-binding transcription factor 4 (Oct-4), C-X-C chemokine receptor type 4 (CXCR4), SRY-box containing gene 2 (SOX2) and mesenchymal-epithelial transition factor (MET) in the eutopic endometrial cells from females with or without endometriosis (second set of samples) measured by real-time polymerase chain reactin (PCR). Values are expressed as the means \pm standard error of the mean (SEM; $n=3)$.

(Fig. 3). However, these differences were not statistically significant. Increased mRNA expression of undifferentiated stem cell markers in the first and second sets of samples nevertheless suggests that there is a relevant connection between undifferentiated stem cells and endometriosis.

Confirmation of CRMP2 as a candidate endometriosis marker by 2-DE analysis of the second set of samples. A second 2-DE analysis was performed to confirm the candidate biomarker proteins identified by the first 2-DE analysis. Among the three candidate proteins (CRMP2, UCH-L1 and MYL9) identified by 2-DE analysis of the first set of samples, only CRMP2 expression demonstrated a change of $>2$-fold (Fig. 4B). Therefore, CRMP2 was selected for further western blot analysis of eutopic endometrial cells in menstrual blood collected from three controls and three patients with advanced endometriosis. Western blot results demonstrated that CRMP2 protein levels were 2.5 -fold higher in the controls compared to that of the endometriosis patients (Fig. 4C and D).

\section{Discussion}

Stem cells are undifferentiated cells capable of self-renewal, proliferation and production of a large number of differentiated daughter cells (1-4). The menstrual cycle is characterized by the growth of endometrial tissues and blood vessels. After menstruation, the proliferative stage of endometrial tissues is initiated by increasing levels of circulating estrogen (25). The isolated small pluripotent stem cells (2-3 min diameter) co-expressing embryonic stem cell markers, including Oct-4 and SOX2, are from human umbilical cord blood (26). The small round cells obtained by ovarian surface epithelium isolation express early embryonic developmental markers, including stage-specific embryonic antigen-4 (SSEA-4) surface antigen, as well as Oct-4, NANOG, SOX2 and c-kit (27). By contrast, pluripotent stem cells expressing Oct-4, SSEA-4, CXCR4 and MET are present in human and mice bone marrow (28).

In the present study, results demonstrated that the mRNA expression of stem cell marker genes (Oct-4, CXCR4, SOX2 
A

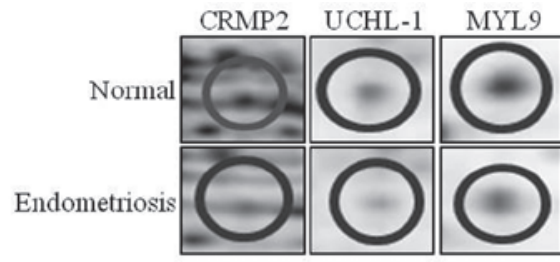

B

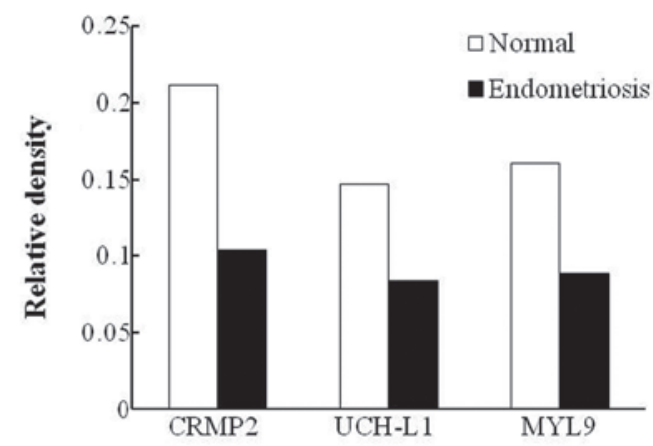

C

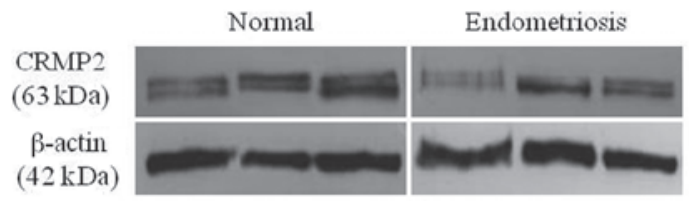

D

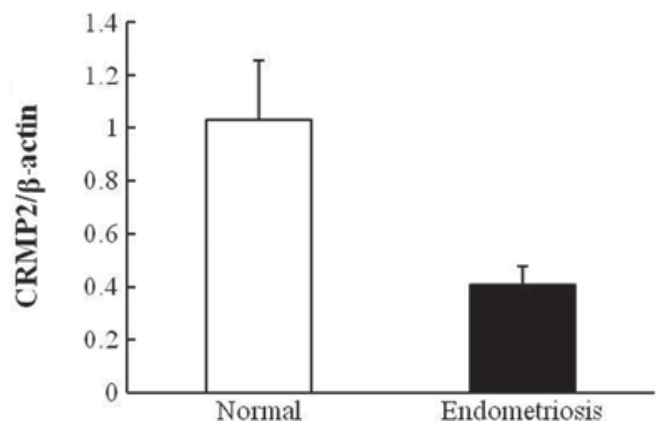

Figure 4. Validation of the candidate endometrial biomarker proteins by (A and B) two-dimensional electrophoresis (2-DE) and (C and D) western blot analysis (second set of samples). Values are expressed as the means \pm standard error of the mean (SEM; $n=3$ ).

and c-MET) was higher in eutopic endometrial cells from the menstrual blood of patients with endometriosis compared to those from the controls (Figs. 1 and 3). The proliferation of stem cells during endometriosis may play a role in endometriotic implantation. Results indicated that the menstrual blood-derived endometrial cells we isolated express stem cell markers and possess characteristics of stem cells. Proteomic studies have helped elucidate the function of specific proteins at the tissue, organ and cellular levels. Using a 2-DE method to compare healthy and pathological states is likely to not only increase our general understanding of a disease at the molecular level, but also provide a driving force to accelerate the identification of biomarkers for the prediction, diagnosis and treatment of diseases. Moreover, microarray and 2-DE analyses have demonstrated that the gene and protein expression profiles of ectopic endometrial implants differ from those of the eutopic endometrium $(29,30)$.
Three proteins were selected as candidate biomarkers of endometriosis based on the first round of 2-DE analysis. In addition, the 2-DE analysis of the second round demonstrated that the CRMP2 protein expression was 2.21-fold higher in healthy individuals compared to endometriosis patients. This significantly higher expression of CRMP2 was confirmed by western blotting (Fig. 4). CRMP2 is a member of the CRMP family with five isoforms, and develops in the neuronal system. This protein does not have enzymatic activity; however, it is involved in neuronal differentiation, axonal guidance and neuronal polarity (31). Overexpression of CRMP2 induces the growth of axons, neurites and dendrites $(32,33)$. At the same time, CRMP2 promotes the elongation and branching of axons by stimulating microtubule assembly after forming a complex with tubulin heterodimers (34). In addition, CRMP2 inhibits axonal growth by regulating phosphorylation via glycogen synthase kinase (GSK)-3 $\beta$ signaling (31). It was shown that CRMP2 phosphorylation is directly and indirectly regulated by CRMP2 directly binding to the $\mathrm{C}$-terminal of neurofibromin in PC12 cells (34). Neurofibromin, a protein produced by the tumor suppressor gene $N F 1$, also acts as a negative regulator of Ras via the Ras-GTPase-activating protein (Ras-GAP) pathway. Neurofibromin directly regulates CRMP2 by forming a complex to control its phosphorylation and indirectly regulates CRMP2 by inhibiting CRMP2 phosphorylation via its function in the Ras-GAP pathway (34). Another study demonstrated that the protein expression is affected by the phosphorylation of CRMP2 (35). Therefore, higher levels of phosphorylated CRMP2 result in higher total CRMP2 protein expression since the phosphorylation of CRMP2 induces protein synthesis and/or inhibits protein degradation. An NF1 gene mutation in mast cells was shown to stimulate angiogenesis $(35,36)$. These mast cells may be involved in the progression of endometriosis. According to Kempuraj et al, the number of mast cells is significantly increased in endometriosis patients (37). Stem cell factor (SCF) is a mast cell growth factor. SCF levels are increased in the peritoneal fluid of endometriosis patients (38). This finding suggests that CRMP2 may increase the proliferation of mast cells in the peritoneum (37). SCF activates mast cells and SCF receptors have been identified in the tissues of endometriosis patients (38).

Taken together, these findings indicate that CRMP2 is not directly involved in the regulation of endometriosis. However, this factor may be involved in the regulation of endometriosis indirectly due to its signals and mediators, including NF1. In conclusion, CRMP2 may be a protein associated with endometriosis and may play an important role in the pathogenesis of this condition.

\section{Acknowledgements}

This study was supported by Medical Research Institute Grant (2010-12), Pusan National University Hospital.

\section{References}

1. Sasson IE and Taylor HS: Stem cells and the pathogenesis of endometriosis. Ann NY Acad Sci 1127: 106-115, 2008.

2. Fox H: The pathology of endometriosis. Ir J Med Sci 152 (Suppl 2): 9-13, 1983. 
3. Gargett CE: Uterine stem cells: what is the evidence? Hum Reprod Update 13: 87-101, 2007.

4. Figueira PG, Abrão MS, Krikun G and Taylor HS: Stem cells in endometrium and their role in the pathogenesis of endometriosis. Ann NY Acad Sci 1221: 10-17, 2011.

5. D'Hooghe TM, Bambra CS, Raeymaekers BM, De Jonge I, Lauweryns JM and Koninckx PR: Intrapelvic injection of menstrual endometrium causes endometriosis in baboons (Papio cynocephalus and Papio anubis). Am J Obstet Gynecol 173: 125-134, 1995.

6. Du H and Taylor HS: Contribution of bone marrow-derived stem cells to endometrium and endometriosis. Stem Cells 25: 2082-2086, 2007.

7. Du H and Taylor HS: Stem cells and female reproduction. Reprod Sci 16: 126-139, 2009

8. Murk W, Atabekoglu CS, Cakmak H, Heper A, Ensari A, Kayisli UA and Arici A: Extracellularly signal-regulated kinase activity in the human endometrium: possible roles in the pathogenesis of endometriosis. J Clin Endocrinol Metab 93: 3532-3540, 2008.

9. Kim CM, Oh YJ, Cho SH, Chung DJ, Hwang JY, Park KH, Cho DJ, Choi YM and Lee BS: Increased telomerase activity and human telomerase reverse transcriptase mRNA expression in the endometrium of patients with endometriosis. Hum Reprod 22: 843-849, 2007.

10. Götte M, Wolf M, Staebler A, Buchweitz O, Kelsch R, Schüring AN and Kiesel L: Increased expression of the adult stem cell marker Musashi-1 in endometriosis and endometrial carcinoma. J Pathol 215: 317-329, 2008

11. Ruiz A, Salvo VA, Ruiz LA, Báez P, García M and Flores I: Basal and steroid hormone-regulated expression of CXCR4 in human endometrium and endometriosis. Reprod Sci 17: 894-903, 2010.

12. Kim JB, Greber B, Araúzo-Bravo MJ, Meyer J, Park KI, Zaehres H, Zaehres $\mathrm{H}$ and Schöler HR: Direct reprogramming of human neural stem cells by OCT4. Nature 461: 649-653, 2009.

13. Huangfu D, Osafune K, Maehr R, Guo W, Eijkelenboom A, Chen S, Muhlestein W and Melton DA: Induction of pluripotent stem cells from primary human fibroblasts with only Oct4 and Sox2. Nat Biotechnol 26: 1269-1275, 2008.

14. Götte M, Wolf M, Staebler A, Buchweitz O, Kiesel L and Schüring AN: Aberrant expression of the pluripotency marker SOX-2 in endometriosis. Fertil Steril 95: 338-341, 2011.

15. Pacchiarotti A, Caserta D, Sbracia $M$ and Moscarini $M$ : Expression of oct- 4 and c-kit antigens in endometriosis. Fertil Steril 95: 1171-1173, 2011

16. Hanash S: Disease proteomics. Nature 422: 226-232, 2003.

17. Ahram M and Petricoin EF: Proteomics discovery of disease biomarkers. Biomark Insights 3: 325-333, 2008.

18. Poliness AE, Healey MG, Brennecke SP and Moses EK: Proteomic approaches in endometriosis research. Proteomics 4 1897-1902, 2004.

19. Gupta S, Agarwal A, Sekhon L, Krajcir N, Cocuzza M and Falcone T: Serum and peritoneal abnormalities in endometriosis: potential use as diagnostic markers. Minerva Ginecol 58: 527-551,2006

20. Ferrero S, Gillott DJ, Remorgida V, Anserini P, Leung KY Ragni N and Grudzinskas JG: Proteomic analysis of peritoneal fluid in women with endometriosis. J Proteome Res 6: 3402-3411, 2007.

21. Zhang H, Niu Y, Feng J, Guo H, Ye X and Cui H: Use of proteomic analysis of endometriosis to identify different protein expression in patients with endometriosis versus normal controls. Fertil Steril 86: 274-282, 2006

22. Livak KJ and Schmittgen TD: Analysis of relative gene expression data using real-time quantitative PCR and the 2[-Delta Delta C(T)] Method. Methods 25: 402-408, 2001.

23. Desrivières S, Prinz T, Castro-Palomino Laria N, Meyer M Boehm G, Bauer U, Schäfer J, Neumann T, Shemanko C and Groner B: Comparative proteomic analysis of proliferating and functionally differentiated mammary epithelial cells. Mol Cell Proteomics 2: 1039-1054, 2003.
24. Jin YC, Lee HG, Xu CX, et al: Proteomic analysis of endogenous conjugated linoleic acid biosynthesis in lactating rats and mouse mammary gland epithelia cells (HC11). Biochim Biophys Acta 1804: 745-751, 2010

25. Patel AN,Park E, Kuzman M, Benetti F, Silva FJ and Allickson JG Multipotent menstrual blood stromal stem cells: isolation, characterization, and differentiation. Cell Transplant 17: 303-311, 2008.

26. McGuckin C, Jurga M, Ali H, Strbad M and Forraz N: Culture of embryonic-like stem cells from human umbilical cord blood and onward differentiation to neural cells in vitro. Nat Protoc 3 1046-1055, 2008

27. Virant-Klun I, Rozman P, Cvjeticanin B, Vrtacnik-Bokal E, Novakovic S, Rülicke T, Dove P and Meden-Vrtovec H: Parthenogenetic embryo-like structures in the human ovarian surface epithelium cell culture in postmenopausal women with no naturally present follicles and oocytes. Stem cells Dev 18: 137-149, 2009.

28. Kucia M, Reca R, Campbell FR, Zuba-Surma E, Majka M, Ratajczak J and Ratajczak MZ: A population of very small embryonic-like (VSEL) CXCR4(+)SSEA-1(+)Oct-4+ stem cells identified in adult bone marrow. Leukemia 20: 857-869, 2006.

29. Filigheddu N, Gregnanin I, Porporato PE, Surico D, Perego B, Galli L, Patrignani C, Graziani A and Surico N: Differential expression of microRNAs between eutopic and ectopic endometrium in ovarian endometriosis. J Biomed Biotechnol 369549-369578, 2010 .

30. Chehna-Patel N, Sachdeva G, Gajbhiye R, Warty N and Khole V: 'Spot'-ting differences between the ectopic and eutopic endometrium of endometriosis patients. Fertil Steril 94: 1964-1971, 2010.

31. Yoshimura T, Kawano Y, Arimura Y, Kawabata S, Kikuchi A and Kaibuchi K: GSK-3beta regulates phosphorylation of CRMP-2 and neuronal polarity. Cell 120: 137-149, 2005.

32. Arimura N, Menager C, Fukata Y and Kaibuchi K: Role of CRMP-2 in neuronal polarity. J Neurobiol 58: 34-47, 2004

33. Fukata Y, Itoh TJ, Kimura T, Ménager C, Nishimura T, Shiromizu T, Watanabe H, Inagaki N, Iwamatsu A, Hotani $\mathrm{H}$ and Kaibuchi K: CRMP-2 binds to tubulin heterodimers to promote microtubule assembly. Nat Cell Biol 4: 583-591, 2002

34. Patrakitkomjorn S, Kobayashi D, Morikawa T, Wilson MM, Tsubota N, Irie A, Ozawa T, Aoki M, Arimura N, Kaibuchi K, Saya $\mathrm{H}$ and Araki N: Neurofibromatosis type 1 (NF1) tumor suppressor, neurofibromin, regulates the neuronal differentiation of PC12 cells via its associating protein, CRMP-2. J Biol Chem 283: 9399-9413, 2008

35. Yang FC, Chen S, Clegg T, et al: Nf1+/- mast cells induce neurofibroma like phenotypes through secreted TGF-beta signaling. Hum Mol Genet 15: 2421-2437, 2006.

36. Le LQ and Parada LF: Tumor microenvironment and neurofibromatosis type I: connecting the GAPs. Oncogene 26: 4609-4016, 2007.

37. Kempuraj D, Papadopoulou N, Stanford EJ, Christodoulou S, Madhappan B, Sant GR, Solage K, Adams T and Theoharides TC: Increased numbers of activated mast cells in endometriosis lesions positive for corticotropin-releasing hormone and urocortin. Am J Reprod Immunol 52: 267-275, 2004.

38. Osuga Y, Koga K, Tsutsumi O, Igarashi T, Okagaki R, Takai Y, Matsumi H, Hiroi H, Fujiwara T, Momoeda M, Yano T and Taketani Y: Stem cell factor (SCF) concentrations in peritoneal fluid of women with or without endometriosis. Am J Reprod Immunol 44: 231-235, 2000. 